\title{
Revitalisasi Tari Tradisi di Situasi Pandemi
}

\author{
Lilis Sumiati ${ }^{1}$, Asep Jatnika ${ }^{2}$ \\ Institut Seni Budaya Indonesia (ISBI) Bandung \\ Jalan Buahbatu nomor 212, Kode Pos 40286 \\ ${ }^{1}$ lilissumiati1411@gmail.com, ${ }^{2}$ asep_jatnika.ac.id
}

\begin{abstract}
Wayang dance is one of the traditional dances that grow and thrive in West Java. One of them grow in Sumedang which created by Raden Ono Lesmana Kartadikusumah since 1930s. After about 90 years, yudawiyata dance went extinct. Therefore, it leads to the formation of motivation to revitalize. This rationale is based on that the dance becomes the only form of puppet war dance work paired with Sumedang style. This dance was realized in 1957, which depicts two satria people practicing war before entering the battlefield. The revitalization is taken with two steps there are reconstruction and implementation. The reconstruction step uses the approach of interpretation that consists of (to express), (to explain), and (to translate) on the other hand the creativity directed to the field of arrangement. The relevant method in the revitalization field is Participation Action Research (PAR). This method is aligned to this research because it consists of participation, research, and action cycle. Participation is a caring action to revive the Yudawiyata dance that was extinct by doing the reconstruction. This caring action is based on previous research. The action is an activity of reconstruction and implementation in Yudawiyata dance. The implementation step is taken by a hybrid of offline and online practice in Padepokan Sekar Pustaka.
\end{abstract}

Keyword: Yudawiyata dance, reconstruction, creativity, implementation

\begin{abstract}
ABSTRAK
Tari Wayang merupakan salah satu tari tradisi yang tumbuh dan berkembang di Jawa Barat. Salah satunya berkembang di Sumedang yang diciptakan oleh Raden Ono Lesmana Kartadikusumah sejak tahun 1930-an. Setelah menapaki sekitar 90 tahun, tari Yudawiyata mengalami kepunahan. Oleh karena itu, menggiring pembentukan motivasi untuk melakukan revitalisasi. Dasar pemikiran ini dilandasi bahwa tari tersebut menjadi satu-satunya bentuk karya tari perang wayang berpasangan gaya Sumedang. Tarian ini diwujudkan pada tahun 1957, yang menggambarkan tentang dua orang satria sedang berlatih perang sebelum memasuki medan laga. Upaya revitalisasi ini ditempuh dengan dua tahap yakni rekonstruksi dan implementasi. Tahap rekonstruksi menggunakan pendekatan interpretasi yang memuat (to ekspress), (to explain), dan (to translate) sedangkan kreativitas diarahkan pada ranah gubahan. Metode yang dianggap relevan dalam ranah revitalisasi yakni Participation Action Research (PAR). Metode tersebut memiliki kesinambungan, karena memuat siklus partisipasi, riset, dan aksi. Partisipasi merupakan bentuk sikap kepedulian untuk menghidupkan kembali tari Yudawiyata yang sudah punah, melalui rekonstruksi. Bentuk kepedulian tersebut dilatarbelakangi dengan adanya riset yang dilakukan sebelumnya. Kemudian aksi merupakan bentuk aktivitas dalam melakukan rekonstruksi dan implementasi tari Yudawiyata. Tahap implementasi dilakukan melalui pelatihan secara hybrid antara luring dan daring di Padepokan Sekar Pusaka
\end{abstract}

Kata kunci: tari yudawiyata, rekonstruksi, kreativitas, implementasi 


\section{PENDAHULUAN}

Seni tradisi menunjuk pada suatu kondisi seni yang telah mengalami fase kehidupan secara turun menurun dengan durasi waktu yang cukup lama. Seni dapat bertahan hidup ditenggarai dengan adanya pola pewarisan yang lengkap. Pola pewarisan yang dimaksud seperti dijelakan oleh CavalliSforza dan Peidman (dalam Berry, 1999, hlm. 32) bahwa pewarisan budaya memiliki tiga bentuk yaitu pola 'pewarisan tegak' (vertical transmission), mendatar, dan miring. Ketiga pola ini sebagai upaya saling menguatkan pelestarian antara pihak keluarga, pendidikan non formal, dan pendidikan formal. Perihal tersebut, sebagaimana di jelaskan Sumiati (2014, hlm. 188) bahwa bentuk pewarisan/ pemindahan tegak, orang tua mewariskan nilai, keterampilan, keyakinan, motif budaya, dan sebagainya kepada anak-cucu. Pola pemindahan mendatar adalah apabila seseorang belajar dari sebayanya yang dimulai sejak lahir sampai dewasa. Adapun pola pewarisan miring dimaksudkan sebagai ajang belajar seseorang dari orang dewasa dan lembaga-lembaga.

Namun demikian, walaupun ketiga pola pewarisan terdapat dalam fenomena pertumbuhan tari wayang Sumedang, pada kenyataannya masih ada yang terlupakan dan akhirnya punah seperti tari Yudawiyata. Untuk menghidupkan kembali tari yang sudah punah, perlu strategi yang tepat salah satunya dengan cara rekonstruksi dan revitalisasi.

Rekonstruksi secara harfiah bermakna sebagai upaya menyusun kembali puingpuing yang sudah berserakan dan bahkan hilang tanpa jejak. Puing-puing tersebut dapat berupa fisik atau nonfisik. Perihal ini, sebagaimana dijelaskan Sumiati (2020, hlm. 146) bahwa rekonstruksi artinya dilakukan penyusunan kembali seperti semula, berdasarkan referensi berupa fisik dan non fisik. Referensi fisik berupa data secara tertulis hasil dari penelitian, buku, dan karya ilmiah sedangkan non fisik merupakan referensi yang bersifat wacana melalui wawancara.

Berdasarkan pada pernyataan tersebut sangat dimungkin untuk ditindaklanjuti, mengingat referensi fisik dan non fisik tentang tari yudawiyata masih ada. Referensi fisik dapat ditemukan pada dokumen yang masih tersimpan oleh pihak keluarga. Dokumen tersebut berupa tulisan tangan Ono, yang menjelaskan arti dan gambaran dari tari yudawiyata. Kemudian nara sumber sekunder sebagai referensi non fisik juga masih dapat ditemui. Ade Rukasih merupakan nara sumber yang kualifikasinya dapat dipertanggungjawabkan. Ia sebagai salah satu murid Ono yang masih memiliki tanggung jawab dalam melestarikan tari-tarian karya Ono.

Revitalisasi ini bertujuan untuk melestarikan tari Yudawiyata yang kemudian dapat dimanfaatkan sebagai materi ajar di dalam pendidikan formal atau non formal. Selain itu, tarian ini dapat dijadikan materi pada kalender event di setiap tempat wisata sehingga meningkatkan daya tarik destinasi wisata tersebut. Dengan demikian, terjalin kolaborasi yang sinergis sehingga tercipta sistem simbiosis mutualisme. 


\section{METODE}

Metode yang diterapkan menggunakan Participation Action Reseach (PAR). Metode PAR menurut Norman K. Denzin (2009, hlm 424-428) terdiri atas tiga kata yang membentuk daur (siklus) dan saling berkaitan satu dengan yang lainnya yakni partisipasi, riset, dan aksi. Partisipasi merupakan bentuk sikap kepedulian untuk menghidupkan kembali tari Yudawiyata yang sudah punah, melalui rekonstruksi. Bentuk kepedulian tersebut dilatarbelakangi dengan adanya riset yang dilakukan sebelumnya. Kemudian aksi merupakan bentuk aktivitas dalam melakukan revitalisasi. Aktivitas ini mengarah pada tatanan rekonstruksi dan implementasi tari perang wayang gaya Sumedang.

Realisasi dari aktivitas tersebut dibagi menjadi beberapa tahapan yakni nyantrik, penguasaan hasil penyadapan, rekonstruksi, penerapan hasil rekonstruksi kepada penari, latihan gabungan dengan pangrawit menggunakan iringan gamelan, rekaman audio, rekaman visual, upload video ke kanal youtube, implementasi kepada masyarakat di Padepokan Sekar Pusaka, dan evaluasi.

Untuk menggali kembali tarian ini membutuhkan setidaknya nara sumber sekunder yang sempat mengetahui wujud dari objek tersebut. Oleh kareana itu, penelitian ini menggunakan pendekatan interpretasi untuk mengeksplanasi pengalaman yang dijelaskan nara sumber.

\section{HASIL DAN PEMBAHASAN}

Tari wayangSumedang sebagai salah satu seni tradisi yang hidup di Priangan, memiliki sistem pewarisan yang kuat dibanding dengan daerah lainnya. Hadirnya tari Wayang gaya Sumedang di tengah masyarakat ini, menurut Sumiati (2014, hlm. 4) dapat ditinjau secara kuantitas yakni terdapat sepuluh tarian yang di antaranya mencakup tari Jayengrana, tari Ekalaya, tari Jakasona, tari Dipati Karna, tari Abimanyu, tari Gatotkaca, tari Antareja, tari Gandamanah, tari Yudawiyata, dan tari Srikandi. Karya-karya tersebut terwujud atas daya kreativitas seniman Sumedang, yaitu Raden Ono Lesmana Kartadikusumah sejak tahun 1930-an. Kurang lebih 90 tahun, karya tersebut hadir di tengah masyarakat. Rentang yang sangat panjang ini, telah mengubah keeksisannya di masyarakat, mengingat empat karya tari telah mengalami fase hampir punah dan punah serta enam karya lainnya masih dapat ditemui dan dipelajari. Di antara keempat karya tari yang keberadaannya sangat menghawatirkan tersebut, salah satunya tari Yudawiyata.

Pemilihan tari Yudawiya sebagai objek dalam kegiatan rekonstruksi ini, di antaranya karena: 1) tari Yudawiyata menjadi satusatunya tari perang Wayang berpasangan di Sumedang; 2) belum terwariskannya tarian ini kepada masyarakat; 3) masyarakat tidak mengetahui baik nama maupun bentuk tari Yudawiyata; dan 4) tertuangnya latar belakang kehidupan Ono dalam tari Yudawiyata.

Mengingat tari Yudawiyata yang sedang mengalami fase punah maka dari itu, untuk membangkitkan kembali pertumbuhannya diperlukan proses rekonstruksi dan revitalisasi yang hasilnya dapat diimplementasikan pada masyarakat Kabupaten Sumedang.

Istilah rekonstruksi telah diungkapkan 
Bhaskara (dalam Susanti, 2018, hlm. 39) dikatakan bahwa "untuk membangkitkan kembali kesenian-kesenian tradisional yang sudah lama tidak terdengar kabar beritanya, tidak ada jalan lain yang bisa dilakukan selain melakukan rekonstruksi". Kemudian Susanti (2018, hlm. 39-40) melanjutkan bahwa:

"rekonstruksi tariadalah sebuah aktivitas yang menggambarkan suatu kejadian melalui asal usul, tentang keberadaan yang ditinjau dari aspek sejarah, gerak, iringan, elemen-elemen gerak yaitu mimik yang diiringi dengan musik sebagai media penyampaian pesanpesan tertentu. Dengan rekonstruksi dimaksudkan pembuatan baru dari apa yang pernah ada tetapi pada saat sekarang tidak atau hampir tidak ada lagi".

Sementara itu, Giddens dalam Beilharz (2002, hlm. 192-193) berpendapat bahwa "gagasan untuk merekonstruksi teori sosial dengan jalan melakukan kritik terhadap tiga mazhab pemikiran sosial terpenting yakni sosiologi interpretatif, fungsionalisme dan strukturalisme". Berdasarkan beberapa penjelasan tersebut, dapat disimpulkan bahwa rekonstruksi merupakan sebuah upaya mewujudkan kembali karya seni yang mengalami kepunahan, dengan dibantu oleh data-data yang menyertainya dan daya interpretasi sebagai aspek penguat kreativitas. Upaya tersebut, untuk memperbaharui struktur agar kualilifikasinya meningkat sehingga dapat berfungsi sesuai harapan. Sementara itu, revitalisasi merupakan suatu upaya atau perbuatan penghidupan/ penggiatan kembali suatu objek yang disampaikan kepada masyarakat.
Kegelisahan telah terjadinya kepunahan yang dialami oleh tari Yudawiyata tersebut, menjadi sebuah motivasi untuk melakukan upaya pembangkitan kembali hingga dilakukannya pelestarian. Pekerjaan melestarikan seni tradisi pada zaman postmodernisme bukanlah merupakan suatu hal yang sia-sia, karena Piliang (2007, hlm. 100) mengatakan bahwa:

"kelahiran postmodernisme berarti kelahiran kembali tradisi (return of the tradition), dalam bentuk, posisi, dan konteks yang baru". Menanggapi pendapat tersebut, dapat dimaknai sebagai kelahiran kembali seni tradisi dalam teks dan konteks baru, tampilan baru yang menggiring semangat baru sesuai dengan zamannya. Bukan diartikan sebagai pengulangan, reproduksi, atau repetisi tradisi (repetition) yang menjadi kebiasaan (habit) sebelumnya.

Untuk mewujudkan rekonstruksi bentuk tari yudawiyata pada intinya memerlukan daya interpretasi dan daya kreativitas. Reinterpretasi menurut Nurcahyanti ( 2021, hlm. 46) memiliki fungsi konstruksi ulang terhadap pandangan lama. Dengan demikian, padahakikatnyainterpretasimerupakanupaya pemaknaan secara personal untuk mengupas arti dari objek, aktivitas, pengungkapan, atau bentuk dari suatu tindakan. Bentuk kupasan sebagai upaya untuk menerjemahkan, membaca, dan melogikakan suatu objek. Daya interpretasi sebagaimana dijelaskan Palmer (2003, hlm 15) terdapat "tiga bentuk yakni mengungkapkan (to ekspress), menjelaskan (to explain), dan menerjemahkan (to translate)".

1. Mengungkapkan (to ekspress) memiliki 
makna sebagai perkataan/pembicaraan yang mengarah padabagaimana ekspresi gaya penampilan tari yudawiyata. Perihal ini, ditempuh dengan media penyadapan atau nyantrik kepada narasumber yang memiliki kualifikasi pada bidangnya. Narasumber sekunder yang dianggap relevan adalah Ade Rukasih. Ia sebagai salah satu murid Ono yang masih eksis mengajar tari wayang Sumedang karya Ono.

Hasil nyantrik mendapatkan sebagian koreografi bagian ngalaga yakni keupat, calik sembah, adeg-adeg, laraskonda, jangkung ilo, mincid, dan pakbang.

Koreografi bagian perang tanding yang menggunakan properti gada, sudah luput dari memori narasumber, sehingga perlu dilakukan rekonstruksi.

2. Menjelaskan (to explain) bersifat rasional dengan cara memahami objek, membentuk, dan memilah, serta menalar dari sesuatu yang diketahui kepada sesuatu yang tidak diketahui.

Pernyataan tersebut dimaksudkan menguasai dan mengetahui tari yudawiyata secara bentuk dan isi yang diserap dari penyadapan.

Isi tari merupakan bagian internal tarian yang tersirat bersifat tidak kasat mata. Adapun bentuk tari merupakan wujud tersurat yang dapat ditangkap oleh panca indera.

Isi tari yudawiyata memiliki lima aspek meliputi latar belakang cerita, gambaran tarian dan tema, nama tarian, karakter, dan unsur filosofis. Latar belakang cerita dari tari yudawiyata bersumber dari cerita wayang Mahabrata yang berkaitan dengan jabatan sebagai prajurit. Gambaran tariannya mengungkapkan para prajurit yang sedang berlatih perang. Oleh karena itu, tema tarian tentang kesiagaan. Nama tari yudawiyata diambil dari dua kata yakni yuda dan wiyata. Yuda berarti perang dan wiyata berarti prajurit. Dengan demikian, nama tarian diambil dari jabatan sebagai prajurit. Prajurit direalisasikan ke dalam tarian dengan jenis kelamin pria yang berkarakter satria ladak. Karakter satria ladak dapat dianalisis dari penggunaan tenaga, ruang, dan waktu. Perihal ini, sebagaimana dijelaskan oleh Rusliana (2016, hlm. 40-41) bahwa karakter satria ladak pada umumnya bergerak dengan tenaga yang sedang, serta ritme dan temponya sedang dan agak cepat; anggota tubuhnya terbuka dengan badan dan arah pandangannya lurus ke depan, level medium dan tinggi ketika berdiri; garis-garis lengannya lengkung dan lurus dengan angkatan kaki ukurannya sebatas betis; menggunakan ruang gerak yang terbuka; dan menggunakan seluruh kualitas geraknya.

Unsur filosofis yang dapat dipetik dari tarian ini mengandung pesan bahwa dalam mengarungi kehidupan senantiasa diiringi dengan kesiapsiagaan dan kewaspadaan dalam menghadapi segala tantangan. Perihal ini, ditenggarai bahwa hidup tidak lepas dari adanya ujian dan cobaan.

Adapun bentuk tari itu sendiri terkait dengan suatu objek yang 
bersifat kasat mata atau dapat dicerna dengan indera. Secara rinci bentuk tari mencakup lima aspek yang meliputi bentuk penyajian, koreografi, rias, busana, dan properti. Bentuk penyajian terkait dengan jumlah penari, yakni tunggal, pasangan, dan kelompok. Tari yudawiyata termasuk pada bentuk penyajian berpasangan karena jumlah penarinya dua orang, ragam geraknya ada yang sama dan berbeda, kedua penari saling merespon dan saling melengkapi.

Koreografi tentunya berupa perwujudan kesatuan sikap, gerak, dan ragam gerak dari awal sampai akhir. Rias dan busana merupakan suatu identitas tarian sebagai pembeda dari setiap repertoar dan genrenya. Sumber bentuk rias dan busana ada yang berpijak pada fenomena keseharian dan ada pula yang mengacu pada latar belakang cerita sehingga bersifat simbolik. Properti tari merupakan alat yang digunakan pada saat menari, seperti sampur/soder, keris, panah, gondewa, gada, bandring, dan lainlain.

3. Menerjemahkan (to translate). Sebagai upaya agar objek dapat dipahami perlu tindakan untuk direalisasikan.

Sebagai pemenuhuan terwujudnya suatu rekostruksi tari Yudawiyata, dapat dibantu dengan daya kreativitas. Daya kreativitas dalam wilayah rekonstruksi terbatas pada koridor menggarap keanekaragaman tarian menjadi wajah baru dengan tetap mempertahankan bentuk dan isi sumbernya. Upaya tersebut salah satu caranya dijelaskan Rusliana (2018, hlm. 186) yakni "merekomposisi koreografi dan menyelaraskan rekomposisi koreografi dengan unsur seni yang menjadi pelengkap keutuhan tari".

Tahapan rekonstruksi sebagaimana telah dijelaskan diimplementasikan melalui interpretasi dan kreativitas, yang realisasinya ditempuh dengan cara eksplorasi, evaluasi, dan komposisi. Eksplorasi merupakan suatu proses penjelajahan gerak dalam merealisasikan pikiran, imajinasi, rasa, dan respon melalui media tubuh dengan mempertimbangkan tenaga, ruang, dan waktu. Pernyataan tersebut, ditegaskan Miroto (2017, hlm. 96) bahwa eksplorasi dalam proses penciptaan seni sebagai tindakan penjelajahan dengan rangsangan dan target tertentu, misalnya eksplorasi gerak patah-patah, eksplorasi properti topeng, eksplorasi adegan perang dengan sumber gerak silat, dan sebagainya". Untuk memudahkan penuangan kreativitas dalam tahap eksplorasi diperlukan daya rangsang. Daya rangsang ini dapat dimotivasi oleh berbagai cara. Perihal tersebut, sebagaimana dipaparkan oleh Bandem (2017, hlm. 157) bahwa utuk menghasilkan gerakan-gerakan dapat dimotovasi dengan melihat sesuatu, memikirkannya, mengkhayalkan, serta merasakan apa yang dikhayalkan dan kemudian menanggapi apa yang dikhayalkan. 
Tahapan yang dilakukan dalam eksplorasi diterapkan juga mengenai pola improvisasi dalam memainkan properti gada. Improvisasi yang dimaksud yaitu melakukan pengolahan gerak tanpa persiapan terlebih dahulu atau dilakukan secara spontanitas. Secara spesifik Sumandiyo (2017, hlm. 15) menjelaskan bahwa:

Improvisasi bidang tari biasanya ditandai dengan unsur spontanitas atau mencoba-coba, sifatnya bersahaja dalam penemuan-penemuan media gerak yang begitu saja terjadi. Oleh karena itu, proses kreatif melalui tahap improvisasi kadang kala diartikan sebagai flight into the unknown atau terbang entah ke mana yang tidak diketahui.

Eksplorasi dalam rekonstruksi tari Yudawiyata dilakukan pengembangan kreativitas namun tidak keluar dari patokanpatokan gaya kelokalan.

Evaluasi dalam rekonstruksi tari diimplementasikan setelah eksplorasi. Evaluasi dapat bermanfaat sebagai tahap analisis dalam menentukan kualitas estetiknya. Perihal ini, sejalan dengan pendapat Lalan Ramlan dkk. (2014, hlm. 26) bahwa evaluasi merupakan kerja analisis atau seleksi terhadap berbagai elemen estetik tari yang dilakukan. Oleh karena itu, dalam tahap ini sebagai rangkaian kegiatan untuk memilih dan memilah ragam gerak hasil eksplorasi. Kemudian dari proses evaluasi ini ditetapkan beberapa ragam gerak yang relevan dengan kaidah tradisi kasumedangan.

Komposisi merupakan tahap akhir dari kerja rekonstruksi yang penebalannya pada proses mewujudkan suatu susunan bentuk tari yang unity dan harmonis. Dengan arti lain, komposisi menurut Sumandiyo (2017, hlm. 25) adalah "bentuk atau wujud karya seni yang hakekatnya menjawab pertanyaan-pertanyaan kreatif (creative question) dianalogikan sebagai kaidah analisis dan penarikan kesimpulan berupa klarifikasi, eksplanasi atau story, yaitu berupa jawaban dari pertanyan-pertanyaan penelitian (research question) yang telah dikemukakan".

Komposisi koreografi hasil rekonstruksi dari tari Yudawiyata terdapat repetisi dari bagian awal sampai tengah dan inovasi dari bagian tengah sampai akhir. Adapun komposisi bentuk tari Yudawiyata dideskripsikan berdasarkan empat aspek yakni koreografi, iringan, rias, dan busana.

Koreografi yang tersusun dari hasil rekonstruksi sebagai berikut:

1. Keupat Satria

Kepret soder kembar, mundur obah tak-tak, cindek kepret soder kembar, Lengkah keupat satria, tangan ayun baplang ngarumbay

2. Calik Sembahan

Adeg-adeg, cindek, lontang kembar, Ukel kembar turun, calik ningkat kiri, sembah. Capang kiri, capang kanan, jungkung kepeng, simpen. Ungkleuk, ukel kiri, ukel kanan, ngumis kanan, jungkung kepeng, simpen. Capang kiri, obah taktak, capang kanan, jungkung kepeng , simpen. Ngayap soder kembar, kepret soder kembar, ukel kembar, sembah, capang kiri, capang kanan, ngaitkeun, jungkung kepeng, simpen.

3. Adeg-adeg

Ngadeg. Capang kanan, sumpingan, 
nyawang, riyeg. Pasang kembar, capang kiri, capang kanan, nyawang, riyeg, dobelan cikalongan (usik malik riyeg).

4. Dobelan

Usik, tumpang tali, sumpingan, nyawang kanan, ukel sembada kanan, riyeg. Ajeg, sumpingan, nyawang kanan, ukel sembada kanan, riyeg. Mundur ukel kembar, cindek.

5. Laraskonda

Adeg-adeg, capang kiri, capang kanan, nyawang kanan, kepret soder kiri.

6. Ungkleuk

Selut kanan, sembada kanan, ungkleuk, riyeg.

7. Raras Trisik

Trisik, ukel kembar, cindek, adegadeg kanan. Pocapa kanan, nengok ka-ki, tenjrag kanan.

8. Jangkung Ilo

Lengkah kanan, tumpang tali, adegadeg kiri, sumpingan kembar, usik, selut kanan, sembada kanan, usik, nyawang kiri, riyeg, sirig nyawang.

9. Laraskonda

Ajeg, pasang. Lengkah kanan tumpang tali, lengkah kiri sembada kanan. Usik, lengkah kiri silang, pasang kanan tumpang tali. Langkah kanan silang, pasang kiri sembada kanan.

10. Mincid Cicing

Ajeg, tangan kiri jiwir soder, tangan kanan tekuk nangreu, ungkleuk, mincid cicing.

11. Raras Dobelan

Langkah ngararas tumpang tali, cindek, nyawang kanan, riyeg. Cindek, adeg-adeg kanan, capang kiri (gambar 39), capang kanan, nyawang kanan, riyeg.
12. Keupat Jiwir Soder

Trisik mundur, obah tak-tak, kepret soder kembar. Lengkahan keupat satria, jiwir soder kiri.

13. Mincid Cirebonan

Lengkahan mincid, lontang kiri. Lengkahan mincid lontang kanan

14. Trisik Dobelan

Ajeg, tincak kaki kanan, ngayap soder kembar, ngalengkah tutup soder ka$k i$, buang soder kembar, kepret capit soder kembar, cindek, sembada soder kanan. Trisik, buang soder kanan, kepret soder kembar.

15. Tincak Tilu

Tincak kaki kanan, sumpingan kanan, tangan kiri bentiknangreu. Lengkah tilu, usik. Tincak kaki kiri, sumpingan kiri, tangan kanan bentik nangreu.

16. Trisik Dobelan

Ajeg, tincak kaki kanan, ngayap soder kembar, ngalengkah tutup soder ka$k i$, buang soder kembar, kepret capit soder kembar, cindek, sembada soder kanan. Trisik, buang soder kanan, kepret soder kembar.

17. Pakblang

Ajeg, tumpang buang soder kanan. Ngalengkah tumpang tali, pasang cindek, adeg-adeg kembar, obah tak-tak. Usik kiri, ukel sembada kiri, rengkuh, ajeg, cindek. Lakukan $3 x$.

18. Sekar Tiba

Trisik ngigir kembang puray, tumpang tali. Trisik ngigir kembang puray, sembada kiri. Trisik ngigir kembang puray, muter, cindek, adeg-adeg pasang lontang kembar. Usik, tumpang tali dobelan. 
19. Kebut Soder

Ngalengkah mundur 2x, ngayap soder kembar. Lengkah gedig jungkung kebut soder (silang pasangan). Adeg-adeg kiri, cindek, tenjrag kiri, saruk kiri, tangan pocapa soder kanan. Sirig, muter kebut soder silang.

Sirig, muter kebut soder silang. Rubuh, calik deku, nungkup soder.

Sirig, tangan pocapa soder kanan, ngalengkah, silang kebut soder, ganti tempat.

\section{Cabokan}

Ajeg, adeg-adeg kiri, nyepeng beubeur pasangan, cindek. Pasang, ngumis kanan, jungkung kepeng, cabok. Rubuh, calik deku. Lakukan 2x bergantian.

Pasang, ngumis kanan, ngayap soder kanan, silang kebut soder, ganti tempat.

21. Trisik Nyandak Gada (Naekeun)

Trisik mucuk soder kanan, langkah kanan miceun soder kanan, langkah kiri kepret soder kembar, nyingsatkeun, calik deku kiri.

Nyandak gada ku tangan kanan, ngadeg calik deku, jungjung gada kepeng. Usik, sembada kiri. Usik, sembada kanan. Usik, sembada kiri. Ngadeg, tenjrag, sirig, tenjrag. Trisik numpang gada.

\section{Perang Gada I}

Ngalepaskeun, muter. Adeg-adeg pocapa kanan gada. Nenggeul gada anca, mundur. Nenggeul gada kerep, maju. Pasang, pocapa gada kanan, nenggeul silang ganti tempat. Usik, neggeul gada silang, trisik.

\section{Perang Gada II}

Ngalepaskeun, muter. Adeg-adeg kanan, nenggeul silang gada, ngadorong, calik deku rubuh. Lakukan 2x bergantian.

Ngadorong gada, mental, muter. Ngalung gada, nyandak gada.

24. Sirig Kepeng

Usik, kepeng kanan nyawang, ngeupeul gada $k u$ tangan kiri, sirig. Tenjrag, jungkung, ngaleng pasangan. Trisik ka luar panggung.

Koreografi yang tersusun tersebut mengacu pada karakter satria ladak baik dalam penggunaan tenaga, ritme, tempo, dan ruang ketubuhan. Sebagai alat ukur penggunaan kualitas gerak dalam tari Yudawiyata diwujudkan dalam karakter satria ladak. Ungkapan tersebut dapat dimaknai bahwa pada saat bergerak menggunakan tenaga yang sedang. Kemudian ritme dan temponya berpola sedang dan agak cepat. Sikap anggota tubuhnya harus terbuka yang ditandai dengan posisi badan dan arah pandangannya lurus ke depan. Ketika penari berdiri pada umumnya menggunakan level medium dan tinggi. Selanjutnya ukuran garis-garis lengan berbentuk lengkung dan lurus. Ketinggian kaki ketika diangkat tidak melebihi betis.

Identitas tersebut sangat penting dipertahankan untuk membedakan karakter yang satu dengan lainnya agar tidak berbaur sehingga nilai-nilai tradisipun tetap terjaga.

Pemaknaan sikap dan gerak dalam tari Yudawiyata memiliki dua ranah yakni murni dan maknawi. Sikap dan gerak murni merupakan pembentukan ragam gerak yang disusun dengan tujuan untuk mendapatkan bentuk estetik dan tidak mempunyai maksudmaksud tertentu. Kemudian sikap dan gerak maknawi merupakan ragam gerak keseharian 
yang sudah distilisasi sehingga mengandung arti atau maksud tertentu.

Koreografi tari Yudawiyata secara garis besar memiliki dua kontek. Bagian pertama (no. 1 sampai 17) lebih mengungkapkan ragam gerak murni. Bagian kedua ragam gerak murni dan maknawi (no. 18 sampai 24).

Iringan menggunakan lagu tumenggung dengan laras salendro. Kemudian iramanya salancar/sawilet naek kering. Struktur iringan seperti ini, tentunya untuk mengatur dinamika dan mendukung suasana tarian

Untuk rias dan busana mengacu pada wayang golek yang berkarakter satria ladak. Oleh karena itu, Sumaryono (2006, hlm. 90) berpendapat rias dan busana yang tidak menggambarkan keseharian disebut dengan simbolis.

Rias simbolik identik dengan rias karakter. Ciri-ciri rias wajah karakter menurut Emy Indaryani (2016, hlm 8) antara lain: (a) garis-garis rias wajah yang tajam, (b) warna-warna yang dikenakan dipilih yang menyolok dan kontras, (c) alas bedak yang digunakan lebih tebal. Rias wajah untuk tari Yudawiyata yang memiliki karakter satria ladak meliputi penajaman garis pada alis, kumis, dan jambang. Dengan demikian, garis alis berbentuk masekon, kumis nyiripit/satria, jambang mecut, kening pasung, dan cedo sebagai hiasan di bawah bibir.

Busana secara umum dipandang sebagai penutup dan pelindung tubuh yang bentuknya beradaptasi dengan fenomena alam, seperti suhu, waktu, dan tempat. Suhu berkaitan erat dengan musim seperti panas, gugur, dingin, dan semi. Waktu lebih disesuikan dengan siang dan malam. Adapun tempat berkaitan

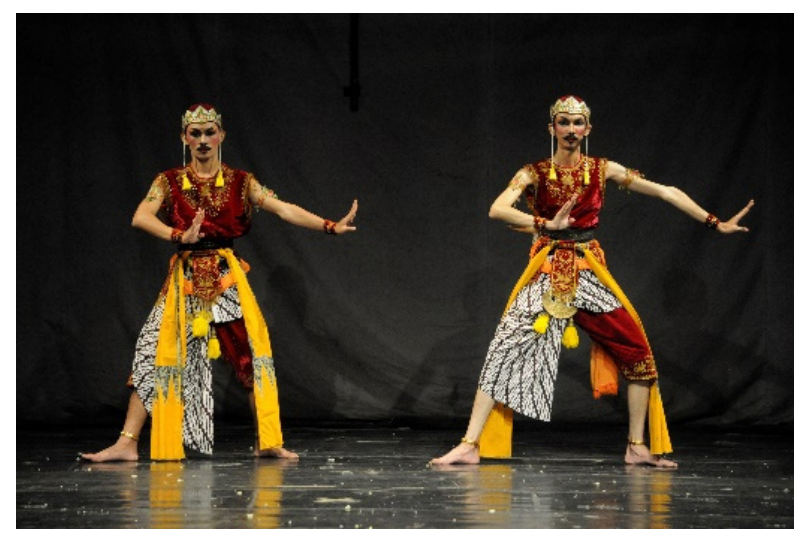

Gambar 1. Busana Tampak Depan (Sumber: Hadi, 2021)

erat dengan berbagai momen atau acara yang dihadiri.

Kemudian pemahaman busana lainnya dijelaskan Sumaryono (2006, hlm. 92) yang meliputi tata busana realis dan tata busana simbolis. Tata busana realis adalah tata busana yang biasa dilihat dalam keseharian. Adapun tata busana simbolis adalah busana yang telah mengalami pengayaan dan bukan keseharian.

Khusus untuk tari Yudawiyata, busananya ditata berdasarkan pada pertunjukan wayang golek. Apabila dikaitkan dengan pendapat Sumaryono maka jenis busana ini termasuk pada simbolis. Busana dan aksesoris tari yudawiyata mulai dari kepala sampai kaki meliputi makuta, baju kutung, celana sontog, sinjang dodot, sampur, beubeur, tutup rasa, kewer, tali ucal, kilat bahu, gelang tangan, dan gelang kaki.

Properti untuk tari Yudawiyata mencakup keduanya yakni bodyprop dan handprop. Properti bodyprop berupa sampur dan handprop berupa gada.

Properti sampur dipilih dari kain shifon yang terbuat dari bahan tipis dan bersifat sangat lentur. Oleh karena itu, sampur ini bisa digerakkan dengan berbagai motif seperti dikepret, diseblak, diteunggeul, dikewong, dan 


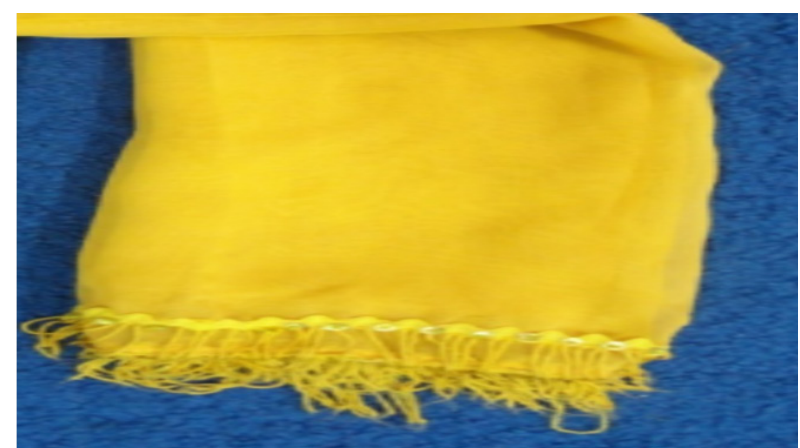

Gambar 2. Sampur

(Sumber: Lilis Sumiati, 2021)

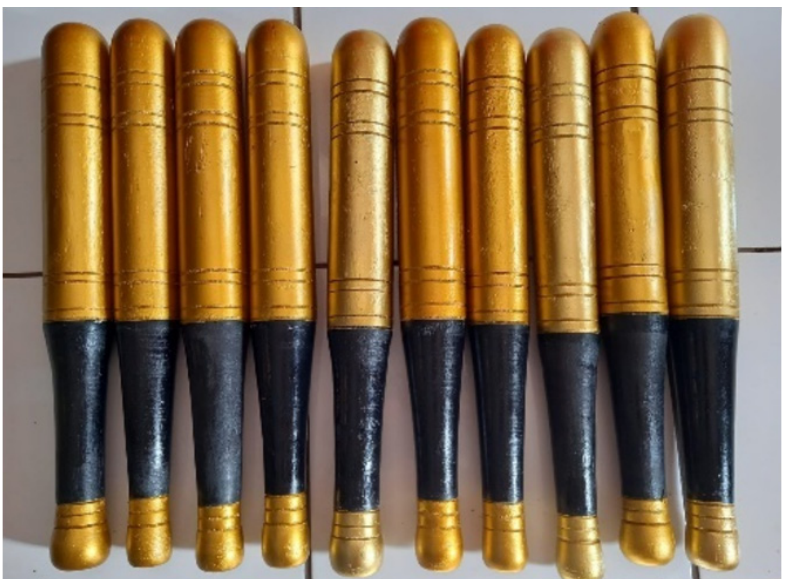

Gambar 3. Gada

(Sumber: Lilis Sumiati, 2021)

lain-lain. Berbanding terbalik dengan properti gada yang terbuat dari kayu, menurut Sumiati (2020, hlm. 148) bahwa sifat gada statis dan kaku dimanfaatkan untuk gerak neunggeul, nyabet, dan lempar.

Setelah bentuk tari yudawiyata selesai direkonstruksi, selanjutnya diperlukan adanya interaksi dengan masyarakat pendukung sebagai bentuk sosialisasi yang mengarah pada penawaran produk tari.

Setelah ada respon baik, maka hasil rekonstruksi tari Yudawiyata mulai diimplemensikan pada masyarakat/ peserta yang tergabung dalam Padepokan Sekar Pusaka. Pemilihan lokasi tersebut dilandasi bahwa padepokan memiliki beberapa potensi yakni:

1. Keberadaan Padepokan Sekar Pusaka, sebagai saksi kontribusi Raden Ono

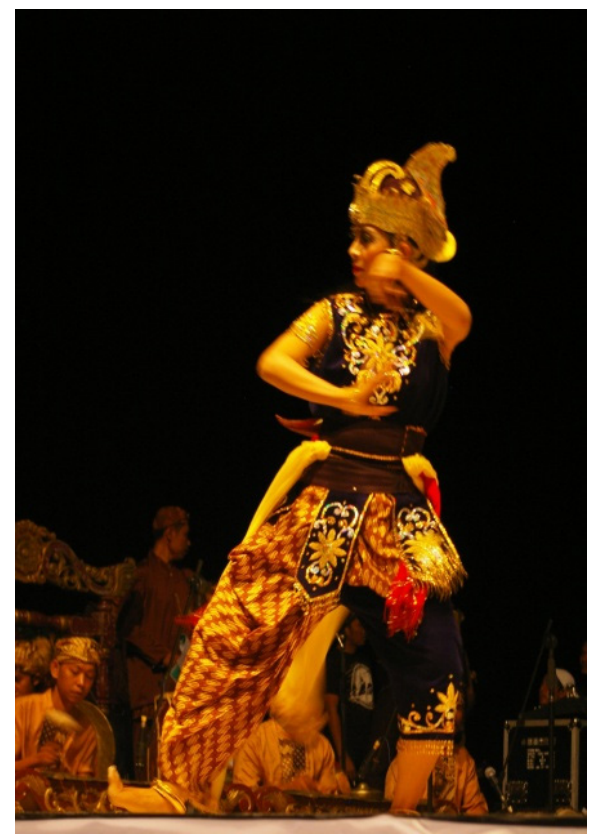

Gambar 4. Widawati sedang Menarikan Tari Jayengrana (Sumber: Wida, 2017)

Lesmana Kartadikusumah yang diwariskan dan dikelola oleh anak dan cucunya.

2. Keberadaan keluarga Ono yang menjadi pewaris dapat berperan sebagai nara sumber atau informan dalam proses rekonstruksi.

3. Ketersediaan bukti-bukti fisik hasil peninggalan Ono, yang dapat memudahkan proses rekonstruksi.

4. Ketersediaan sarana dan prasarana yang lengkap untuk melaksanakan proses rekonstruksi.

5. Memiliki ketersediaan peserta kursus, untuk mengimplementasikan tari yudawiyata hasil rekonstruksi.

Rutinitas Padepokan Sekar Pusaka dalam pemberian materi kepada peserta kursus, dilakukan setiap hari Sabtu mulai pukul 09:00 - 12:00 WIB, dan hari Minggu mulai pukul 15:00 - 17:00 WIB. Pelatih tari dan sekaligus berperan sebagai penerus kepemilikan padepokan yakni Raden Widawati Noer 
Lesmana. Widawatimerupakancucu Onoyang memiliki garis keturunan secara vertikal, ia juga merupakan lulusan Sarjana dan Magister di ISBI Bandung. Kemampuannya dalam Seni Tari ini tak perlu diragukan, hal tersebut dapat dibuktikan karena sejak sepeninggal ayahnya, Padepokan Sekar Pusaka masih tetap eksis hingga saat ini.

Menerapkan tari di masa pandemi bisa dicapai dengan dua hal (hybrid) yaitu luring (offline) dan daring (online). Cara offline, pelatihan langsung datang ke lokasi dan tatap muka sedangkan online adalah pelatihan secara mandiri di rumah masingmasing yang materinya bisa dipelajari di channel youtube. Untuk bahan evaluasinya, peserta mengirimkan videonya melalui whastApp grup (WAG), googleschooler, atau youtube. Proses penyerapan materi secara online tersebut ternyata memiliki kendala di antaranya ada beberapa peserta yang tidak mengirimkan video, penguasaan teknik gerak yang kurang maksimal, dan kurang maksimal hapalan koreografi dari para peserta. Akibat dari dampak pembelajaran daring, peserta belum menghasilkan kualitas yang maksimal. Namun demikian, jika melihat antusias peserta memiliki semangat yang tinggi. Hal ini dapat dibuktikan dengan banyaknya peserta yang mengikuti kegiatan implementasi tari yudawiyata meskipun dibatasi oleh situasi pandemi.

Sisi positif dari adanya pandemi ini mengajarkan manusia untuk cepat beradaptasi dengan situasi dan kondisi di seputar lingkungan. Dalam arti tertentu dapat menghadapi masalah yang terkait dengan kemahiran teknologi industri. Oleh karena itu hasil revitalisasi tari yudawiyata ini juga menerapkan teknologi industri yang berupa film dokumenter yang di-upload melalui channel youtube.

\section{SIMPULAN}

Tari tradisi dalam hal ini tari yudawiyata sudah berhasil direvitalisasi dengan cara direkonstruksi dan diimplementasikan. Rekonstruksi ditempuh dengan menerapkan teori interpretasi dan kreativitas. Interpretasi sebagai jembatan untuk mengetahui dan memahami objek secara mendalam, sedangkan kreativitas diarahkan pada ranah gubahan. Upaya tersebut sebagai benteng agar dalam mengembangkan tarian tetap mempertahankan kaidah-kaidah tradisi. Kaidah-kaidah tersebut terkait dengan ciri khas estetika tari wayang kasumedangan. Sebagai pemenuhan pada koridor revitalisasi, tari yudawiyata hasil rekonstruksi diimplementasikan, dengan maksud agar tarian tersebut mulai lagi dikenal oleh masyarakat. Dengan demikian, kekayaan tari wayang Sumedang setahap demi setahap dapat hidup semarak lagi seperti sedia kala.

\section{DAFTAR PUSTAKA}

Bandem, NLN Suasthi Widjaja. (2017). (dalam Karya Cipta Seni Pertunjukan). Yogyakarta: JB Publisher.

Berry, John W. (1999). Psikologi Lintas Budaya: Riset dan Aplikasi. Jakarta: Gramedia Pustaka Utama. 
Denzin, Norman K. dan Lincoln Yvona S. GLOSARIUM

(2009). Handbook Of Qualitative Research. Penerjemah Dariyatno dkk. Yogyakarta: Pustaka Pelajar.

Indaryani, Emy. (2016). Modul Paket Keahlian Tata Kecantikan Kulit: Rias Karakter dan Fantasi. Jakarta: Kemendikbud.

Ludeman, L. C. (1987). Fundamental of Digital Signal Processing, Singapore, John Wiley \& Sons, Inc.

Miroto, Martinus. (2017). Riset Artistik-Koreografi di Lingkungan Akademis (dalam Karya Cipta Seni Pertunjukan). Yogyakarta: JB Publisher.

Nurcahyanti, Desy dkk. (2021). Mbok Mase dan Mbok Semok: Reinterpretasi Karakter Perempuan Jawa dalam Kultur Batik. Jurnal Panggung V31/N3/09, 46.

Palmer Richard E. (2003). Hermeuneutika: Teori Baru Mengenai Interpretasi, Penerjemah Musnur Hery \& Damanhuri Muhamed. Yogyakarta: Pustaka Pelajar.

Piliang, Yasraf Amir. (2007). Seni Pertunjukan Tradisi dalam Peta Seni Posmodernisme, Jurnal Panggung STSI Bandung 17 (2).

Rusliana, Iyus. (2016). Tari Wayang, Bandung: Jurusan Seni Tari STSI Bandung. . (2018). Tari Wayang, Bandung: Jurusan Tari ISBI Bandung. . (2020). Tari Wayang, Bandung: Jurusan Tari ISBI Bandung.

Sumaryono dan Endo Suand. (2002). Tari Tontonan, Jakarta: Lembaga Pendidikan Seni Nusantara.

Sumiati, Lilis. (2014). “Transformasi Tari Jayengrana Karya R. Ono Lesmana Kartadikusumah: Kajian Dinamika Nilai Estetik." Disertasi. Bandung: Program Doktoral Universitas Padjadjaran.

(2020). Kreativitas Tari Yudawiyata. Jurnal Panggung V30/ N1/01, 146.

Susanti, Dewi. (2018). Rekostruksi Tari Zapin Duo di Kelurahan Teluk Dalam Kecamatan Kuala Kampar Kabupaten Pelalawan Provinsi Riau. Seminar

A

Adeg-adeg : merupakan sikap kaki dengan keadaan kudakuda atau rengkuh yang salah satu kakinya menghadap serong.

Ajeg

Ayun

B

Baplang : sikap tangan membentuk melintang/membentang yang asimetris.

\section{C}

Capang : sikap olahan tangan dengan posisi tangan kiri lurus nangreu dan tangan kanan ditekuk (telapak tangan seperti menempel pada siku bagian dalam dan sebaliknya.

Cabokan : Sikap tangan memukul lawan

Cindek

Cingeus

gerak merendahkan badan dengan diberi hentakan

: Gerak kepala ke menoleh ke kiri, tengah dan kanan tengah dengan ritme yang cepat dan diberi hentakan (stakato)

D

Deku : sikap duduk dengan cara menahan tubuh menggunakan kedua dengkul dan betis lurus ke belakang

Dobelan : Gerakan tangan dengan irama cepat

E

Ecek
: Langkahan kaki dengan tempo cepat Antar Bangsa: Seni Budaya dan Desain: STANSA, 39. 
G

Galeong : gerakan berputar setengah lingkaran dari mulai kepala, tangan, badan, dan kaki yang dilakukan secara perlahan.

Gebes : menolehkan kepala ke kanan, ke kiri, dan serong, dengan hentakan

Gilek

Godeg

: memutar kepala membentuk angka 8 tidur, dengan dahi sebagai porosnya

J

$\begin{array}{lll}\text { Jalak } & : \text { langkahan kaki bergerak } \\ \text { Pengkor } & \begin{array}{l}\text { menyamping dengan } \\ \text { salah satu kaki yang } \\ \text { dibelakang seperti kaki } \\ \\ \text { yang pincang. }\end{array} \\ \text { Jiwir } & : \begin{array}{l}\text { Memegang ujung } \\ \text { selendang atau kain }\end{array}\end{array}$

K

Kembar : Sikap kedua tangan dan kaki yang simetris

Kepret Soder : gerak menggerakkan selendang dengan telapak tangan setelah diayap.

Kepeng : Sikap tangan seperti nyawang

Keupat : Gerak seperti berjalan yang sudah distilisasi

L
Laraskonda : Posisi kaki adeg-adeg dengan sikap tangan capang

$\begin{array}{ll}\text { Lontang } \quad: & \text { Sikap meluruskan } \\ \text { Kembar } & \text { kedua lengan ke depan, } \\ & \text { dengan talapak tangan } \\ & \text { menghadap depan dan } \\ & \text { jari-jarinya ke atas }\end{array}$

M

$\begin{array}{lll}\text { Makuta } & : & \text { Sebutan untuk mahkota } \\ & \text { dalam Sunda } \\ \text { Mucuk } & : & \text { sikap telapak tangan } \\ \text { soder } & \text { menjepit selendang, dan } \\ & \text { dibuat menggantung } \\ & \text { diantara pergelangan } \\ & \text { tangan, yang jari-jari } \\ & \text { tangan menghadap ke atas }\end{array}$

$N$

Ngaleng : Menggandeng

Neunggeul : Memukul

Ngayap : Menyusur selendang

soder

Ngeupeul : Mengepalkan jari tangan

Nyawang : sikap gerak telapak tangan seperti sedang meninjau sesuatu

Nyepeng : Memegang sabuk

beubeur

Ngigir : Bergerak menyamping

O

Obah Tak- : Gerakan naik-turunnya

tak bahu yang bergantian dalam tari Sunda

P

Pocapa : Sikap tangan kanan lurus dengan jemari ke atas dan tangan kiri menekuk di dekat pinggang (atau sebaliknya)

$\mathrm{R}$

Rengkuh : Menurunkan ketinggian dari kedua kaki dan badan

S

Selut

: gerakan olahan tangan seperti sedang membelitkan tali

Sembada : sikap gerak tangan, dimana tangan yang satu lurus di samping, dan yang satunya menekuk di depan pusar, dengan 
kedua telapak mengarah ke samping dan jarijarinya ke atas

Sembah : Gerak maknawi yang sedang menyembah dengan menempelkan kedua telapak tangan, yang ujung dari kedua ibu jari berada dibawah hidung

Sirig $\quad$ : gerakan olahan jari kaki dengan posisi kaki kuda-kuda, dan kedua kaki jingkat. Kemudian bergerak ke samping, yang ukuran geraknya monoton

Soder $\quad$ : istilah lain dalam tari Sunda yang menyebutkan selendang

$\mathrm{T}$

Tenjrag : Menginjak tanah dengan tenaga yang kuat

Tincak tilu : Melangkahkan kaki tiga hitungan dan hitungan kempat cindek

Trisik : Berjalan dengan langkah kecil dan tempo yang cepat

$\mathrm{U}$

Ukel : gerak olahan telapak tangan yang membulat, dan diakhiri dengan jarijari tangan lurus ke atas

Ungkleuk : Menggerakkan kepala ke atas dan ke bawah

Usik : Mengalihkan berat badan dari kaki kiri dan kanan 